\title{
Efektifitas Motivasi Kerja Tenaga Kesehatan Rumah Sakit
}

\author{
Melly, Singgih Tiwut Atmojo ${ }^{a}$

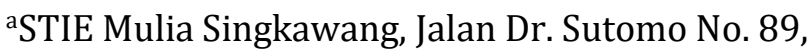 \\ Email: Singkawangmelly.salty@gmail.com, \\ singgihatdmodjo3805@gmail.com
}

(Diterima Agustus 2020; Disetujui November 2020; Dipublikasikan Januari 2021)

\section{ABSTRACT}

The purpose of this research is to determine the influence of hygiene factors and motivational factors that can encourage healt $h$ workers to work more productively at the Hospital of St. Vincentius Singkawang. Sources of data obtained from observations and questionnaires. The data analysis method used in this study is a qualitative method with descriptive statistical data analysis techniques. The population of this research is 118 Vincentius Singkawang Hospital health workers. The sampling technique uses probability sampling. From the results of the analysis, the authors conclude that the leadership has fulfilled the factors of workforce motivation in accordance with financial capabilities. However, there are still factors that have not been well paid attention to is the salary given by the hospital to employees must contain the principle of fairness and refer to the legislation. So that the organization will obtain, maintain, and employ a number of employees with a variety of positive attitudes and behaviors, productive performance, effective and efficient in completing work for the interests of the organization in order to achieve the goals of the St. Vincentius Hospital Singkawang.

Keyword: Motivational Factor, Hygine Factor

\section{PENDAHULUAN}

Seiring dengan meningkatnya pertumbuhan penduduk Indonesia, kebutuhan akan pelayanan kesehatan juga semakin meningkat. Kebutuhan pelayanan kesehatan dapat dipenuhi melalui poliklinik, puskesmas, dan rumah sakit umum. Rumah sakit adalah instansi yang bergerak dibidang pelayanan jasa yang menyelenggarakan pelayanan kesehatan perorangan secara paripurna serta menyediakan pelayanan rawat inap, rawat jalan, gawat darurat dan penunjang. Dalam menjalankan usahanya rumah sakit menggunakan sumber daya manusia yaitu tenaga kesehatan dan non kesehatan.

Tenaga kesehatan terdiri dari tenaga profesi dan tenaga non kesehatan terdiri dari tenaga umum. Menurut Undang-Undang tentang Tenaga Kesehatan pasal 36 tahun 2014Bab I pasal 1: "Tenaga Kesehatan adalah setiap orang yang mengabdikan diri dalam bidang kesehatan serta memiliki pengetahuan dan/atau ketrampilan melalui pendidikan dibidang kesehatan yang untuk jenis tertentu memerlukan 
kewenangan untuk melakukan upaya kesehatan. Tenaga kesehatan memiliki peranan penting untuk meningkatkan kualitas pelayanan kesehatan yang maksimal kepada masyarakat agar mampu untuk meningkatkan kesadaran, kemauan, dan kemampuan hidup sehat sehingga akan terwujud derajatkesehatan yang setinggitingginya sebagai investasi bagi pembangunan sumber daya manusia.

Dalam prakteknya penyelenggaraan upaya kesehatan harus dilakukan oleh tenaga kesehatan yang bertanggung jawab, yang memiliki etik dan moral yang tinggi, keahlian dan kewenangan yang secara terus menerus harus ditingkatkan mutunya melalui pendidikan dan pelatihan berkelanjutan, sertifikasi, registrasi, perizinan serta pembinaan, pengawasan, dan pemantauan agar penyelenggaraan upaya kesehatan memenuhi rasa keadilan dan perikemanusiaan serta sesuai dengan perkembangan ilmu pengetahuan dan teknologi kesehatan.

Dengan demikian, untuk menggerakkan karyawan agar sesuai dengan apa yang dikehendaki oleh perusahaan maka manajer perusahaan harus memahami motivasi manusia yang bekerja dalam perusahaan. Faktor motivasi inilah yang menentukan perilaku orang-orang dalam bekerja". Salah satu bagian dari statistik rumah sakit adalah indikator pelayanan rawat inap rumah sakit. Indikator ini merupakan gambaran tinggi rendahnya penggunaan dan efisiensi pelayanan rawat inap rumah sakit. Indikator pelayanan rawat inap diperoleh dari sensus harian rawat inap. Untuk mengetahui tingkat penggunaan tempat tidur rumah sakit atau Operational Ratio (BOR) dapat dilihat pada Tabel 1 berikut:

Tabel 1. Tingkat BOR Th. $2013-2017$

\begin{tabular}{|l|c|c|c|}
\hline Tahun & BOR \% & Tingkat BOR \% & Ideal BOR \% \\
\hline 2013 & 53,9 & - & 85 \\
\hline 2014 & 71,3 & 32,28 & 85 \\
\hline 2015 & 69,6 & $-2,38$ & 85 \\
\hline 2016 & 69,0 & $-0,86$ & 85 \\
\hline 2017 & 74,4 & 7,83 & 85 \\
\hline
\end{tabular}

Sumber: RS. Santo Vincentius

Dari tabel 1 dapat diketahui bahwa rata-rata penggunaan tempat tidur Rumah Sakit Santo Vincentius dari tahun 2013 - 2017 cukup efisien yaitu Bed Operational Ratio (BOR) berada pada rentang ideal BOR yaitu $85 \%$. Dalam implementasi kepuasan kerja juga mempengaruhi kinerja karyawan dimana untuk melihat kepuasan kerja karyawan dapat dilihat dari seberapa besarmotivasi yang diberikan sehingga mampu meningkatkan motivasi karyawan itu sendiri untuk setia pada perusahaan. Motivasi karyawan pada umumnya dapat dilihat dari tingkat turnover (keluar masuk) dan juga dari tingkat absensi, untuk mengetahui kedua faktor tersebut maka dapat kita lihat pada tabel 2 dan 3 berikut: 
Tabel 2. Tingkat Perputaran Tenaga Kesehatan

\begin{tabular}{|c|c|c|c|c|c|c|}
\hline Tahun & Awal & Masuk & Keluar & Akhir & \multicolumn{2}{|c|}{ Turnover \% } \\
\cline { 5 - 7 } & & & & & Masuk & Keluar \\
\hline 2015 & 147 & 50 & 12 & 185 & 30,12 & 7,23 \\
\hline 2016 & 195 & 16 & 9 & 202 & 8,06 & 4,53 \\
\hline 2017 & 202 & 30 & 20 & 212 & 14,49 & 9,66 \\
\hline
\end{tabular}

Sumber: RS. Santo Vincentius

Tabel 3. Tingkat Absensi Tenaga Kesehatan

\begin{tabular}{|c|c|c|c|c|c|}
\hline $\begin{array}{c}\text { Tahu } \\
\mathrm{n}\end{array}$ & $\begin{array}{c}\text { Jumlah Tenaga } \\
\text { Kesehatan }\end{array}$ & $\begin{array}{c}\text { Hari } \\
\text { Kerja } \\
\text { Efektif }\end{array}$ & $\begin{array}{c}\text { Total Hari } \\
\text { Kerja }\end{array}$ & $\begin{array}{c}\text { Jumlah } \\
\text { Absen }\end{array}$ & $\%$ \\
\hline 2015 & 195 & 294 & 57330 & 114 & 0.20 \\
\hline 2016 & 202 & 298 & 60196 & 156 & 0.26 \\
\hline 2017 & 212 & 294 & 62328 & 493 & 0.79 \\
\hline
\end{tabular}

Sumber: RS. Santo Vincentius

Data tabel 2 menunjukkan jumlah tenaga kesehatan masuk yang tinggi, ini menyebabkan pihak MSDM harus melakukan perekrutan, orientasi, penempatan, pelatihan, monitoring dan evaluasi, dan lain sebagainya yang tentu saja akan memerlukan waktu dan menghabiskan biaya yang tidak sedikit. Masuk dan keluarnya tenaga kesehatan akan berpengaruh terhadap kualitas kinerja karyawan dan mutu pelayanan kepada pasien dan keluarganya.

Berfluktuasinya jumlah absensi dari tahun 2015-2017 menunjukkan adanya perubahan pada motivasi tenaga kesehatan di Rumah Sakit Santo Vincentius Singkawang akan berpengaruh terhadap pekerjaan, tugas dan tanggung jawab dalam pelayanan jasa. Dari data yang diuraikan faktor yang berhubungan dengan perilaku dan produktifitas tenaga kesehatan adalah motivasi. Motivasi kerja tenaga kesehatan diperlukan supaya pelanggan dapat meneriman pelayanan sesuai yang diharapkan, secara konsisten dan berkesinambungan, komprehensif dan professional.

Dengan demikian, tingkat absensi yang tinggi berpengaruh terhadap jadwal dinas dan menghambat penyelesaian pekerjaan, efektifitas dan efisiensi pelayanan kesehatan.

Berdasarkan tingkat perputaran tenaga kesehatan yang tinggi dan fluktuasi yang tinggi tingkat absensi tenaga kesehatan Rumah Sakit Santo Vincentius yang tinggi akan berdampak terhadap kualitas kinerja tenaga kesehatan, efektifitas dan efisiensi pelayanan kesehatan yang berpengaruh pada mutu pelayanan dan kepuasan pasien juga keluarga terhadap pelayanan Rumah Sakit Santo Vincentius. Maka, penulis tertarik melakukan penelitian mengenai "Efektifitas Motivasi Kerja Tenaga Kesehatan Rumah Sakit". 


\section{KAJIAN LITERATUR MSDM}

(Mangkunegara, 2011: 2): "Manajemen sumber daya manusia merupakan suatu proses serta upaya untuk merekrut, mengembangkan, memotivasi serta megevaluasi keseluruhan sumber daya manusia yang diperlukan perusahaan dalam mencapai tujuannya dan sumber daya manusia juga merupakan pendekatan terhadap manajemen manusia. Pendekatan terhadap manajemen manusia tersebut didasarkan pada nilai manusia dalam hubungan organisasi. Manusia merupakan sumber daya yang penting dalam organisasi, disamping itu efektifitas organisasi sangat ditentukan oleh manajmen manusia".

(Hasibuan, 2012: 10): "Manajemen Sumber Daya Manusia adalah ilmu atau seni mengatur hubungan dan peranan tenaga kerja agar efektif dan efisien membantu terwujudnya tujuan perusahaan, karyawan, dan masyarakat". (Umar dalam Sutrisno, 2010: 7): "Dalam tugasnya manajemen sumber daya manusia dapat dikelompokkan atas tiga fungsi, yaitu:

1) Fungsi manajerial: perencanaan, pengorganisasian, pengarahan, dan pengendalian.

2) Fungsi operasional: pengadaan, pengembangan, kompensasi, pengintegrasian, pemeliharaan, dan pemutusan hubungan kerja.

3) Fungsi ketiga adalah kedudukan manajemen sumber daya manusia dalam pencapaian tujuan organisasi perusahaan secara terpadu".

Dari beberapa pendapat para ahli tersebut dapat disederhanakan bahwa manajemen sumber daya manusia adalah suatu proses menangani berbagai masalah pada ruang lingkupkaryawan, pegawai, buruh, manajer, dan tenaga kerja lainnya untuk dapat menunjang aktivitas organisasi atau perusahaan demi mencapai tujuan yang telah ditentukan.

\section{Motivasi}

(Priansa, 2016: 200): “Motivasi berasal dari kata Latin "movere"yang berarti dorongan, daya penggerak atau kekuatan yang menyebabkan suatu tindakan atau perbuatan. Kata "Movere" dalam bahasa Inggris sering disepadankan dengan "Motivation" yang berarti pemberian motif, penimbulan motif, atau hal yang menimbulkan dorongan atau keadaan yang menimbulkan dorongan. Secara harfiah motivasi dipahami sebagai pemberian motif. Pegawai bekerja karena memilki motif. Motif tersebut terkait dengan maksud atau tujuan yang ingin diraihnya. Pada umumnya, motif utama pegawai untuk bekerja adalah mencari penghasilan, mengembangkan potensi diri, aktualisasi, serta kebutuhan akan penghargaan". Pentingnya motivasi karena motivasi merupakan hal yang menyebabkan, menyalurkan dan mendukung perilaku manusia supaya mau bekerja giat dan tekun untuk serta antusias mencapai hasil yang optimal. Motivasi semakin penting karena pimpinan membagikan pekerjaan pada bawahannya untuk dikerjakan dengan baik dan terintegrasi dengan tujuan yang diinginkan.

Para ahli menjabarkan motivasi kedalam beragam defenisi diantaranya:

*corresponding authors e-mail : Singkawangmelly.salty@gmail.com singgihatdmodjo3805@gmail.com 
1) ((Wibowo, 2011: 379): "Motivasi merupakan dorongan terhadap serangkaian proses perilaku manusia pada pencapaian tujuan."

2) Afifudin, 2013: 191): "Motivasi adalah kondisi psikologis dalam diri individu yang menggerakkan individu sehingga terjadi perubahan tingkah laku yang disadari untuk mencapai tujuan".

3) (Nawawi, 2011: 351): "Motivasi adalah suatu kondisi yang mendorong atau menjadi sebab seseorang melakukan suatu perbuatan/kegiatan, yang berlangsung secara sadar",

4) (Mangkunegara, 2011: 93): "Motivasi adalah menggerakkan pegawai agar mampu mencapai tujuan dan motifnya".

Berdasarkan pengertian-pengertian motivasi tersebut maka, sintesis motivasi adalah kondisi psikologis yang muncul dalam diri individu yang mempengaruhi tingkah laku seseorang dalam berusaha dan bertindak untuk mencapai suatu tujuan yang ingin dicapai oleh individu, kelompok maupun organisasi.

\section{Jenis Motivasi}

Dalam penelitian ini penulis menggunakan teori Herzberg, karena lebih mempermudah dalam menganalisis faktortor-faktor motivasi kerja tenaga kesehatan di Rumah Sakit Santo Vincentius Singkawang yang terdiri dari faktor ekstrinsik adalah kebutuhan yang diterima dari luar, orang lain, maupun perusahaan. Faktor ekstrinsik merupakan hak dasar dan dapatmembuat karyawan merasa tentram. Sedangkan faktor intrinsik merupakan kepuasan atas kontribusi yang dirasakan dan diterima pada suatu organisasi tempat bekerja. Jadi, yang dapat membuat karyawan mendapatkan kepuasan dan termotivasi dalam melakukan suatu pekerjaan adalah dengan memperhatikan dan memenuhi faktor yang bersifat intrinsik (kebutuhan dari dalam).

Agar lebih memperdalam penjelasan jenis teori motivasi yang dirujuk dijelaskan dalam pendekatan teori berikut. Frederick Herzberg yang dikutip dalam buku (Suparyadi, 2015: 423): "Teori Motivasional, dan Hygiene meyakini bahwa hubungan seseorang individu dengan pekerjaanya merupakan suatu hubungan dasar dan bahwa sikapnya terhadap kerja sangat menentukan sukses atau tidaknya individu tersebut:

1) Faktor-faktor Hygiene (Gaji, Kebijakan dan administrasi perusahaan., Kondisi kerja. Penyeliaan. Hubungan dengan penyelia. Hubungan dengan rekan kerja. Hubungan dengan bawahan. Hidup pribadi. Status. Keamanan).

2) Faktor-faktor Motivasional (Kerja itu sendiri, Tanggung jawab, Pengakuan., Kemajuan., Pertumbuhan, Prestasi).

Dari hasil penelitiannya Herzberg menarik suatu kesimpulan bahwa faktor-faktor yang menjadi penyebab terjadinya kepuasan dan ketidakpuasan itu berbeda, yaitu bahwa faktor- faktor penyebab terjadinya kepuasan itu bersifat intrinsik, sedangkan yang bersifat ketidakpuasan itu merupakan faktor-faktor ekstrinsik.

Herzberg berpendapat bahwa untuk memuaskan karyawan tidak dengan cara menghilangkan masalah yang ada pada faktor-faktor ekstrinsik, karena menghilangkan masalah faktor ekstrinsik hanya akan membuat karyawan merasa 
tentram, tetapi belum tentu termotivasi. Oleh karena itu, faktor-faktor seperti kebijakan dan administrasi perusahaan, penyeliaan, hubungan antar pribadi, kondisi kerja, dan gaji oleh Herzberg disebut sebagai faktor-faktor hygiene. Jika ingin memotivasi karyawan pada pakerjaannya, Herzberg menyarankan untuk menekankan prestasi, pengakuan, kerja itu sendiri, tanggung jawab, dan pertumbuhan. Faktor-faktor inilah yang dianggap sebagai mengganjar secara intrinsik".

\section{METODE PENELITIAN}

Bentuk metode penelitian yang penulis gunakan dalam penelitian ini adalah metode deskriptif. Menurut (Nazir dalam Andi , 2011: 186): "Metode Deskriptif adalah suatu metode yang digunakan untuk meneliti status sekelompok manusia, suatu set kondisi, suatu pemikiran, ataupun suatu kelas peristiwa pada masa sekarang. Dalam penelitian ini penulis menggunakan teknik pengumpulan data yang terdiri dari Observasi Menurut (Sutrisno dalam Sugiyono, 2012: 196): "Observasi merupakan suatu proses yang komplek, suatu proses yang tersusun dari berbagai proses biologis dan psikologis". Dua diantara yang terpenting adalah proses-proses pengamatan dan ingatan". Selanjutnya Kuesioner (Angket) (Sugiyono, 2012: 192): "Kuesioner merupakan teknik pengumpulan data yang dilakukan dengan cara memberi seperangkat pertanyaan atau pernyataan tertulis kepada responden untuk dijawabnya".

Populasi dan Sampel dalam penelitian ini yaitu populasi merupakan keseluruhan subyekyang akan diteliti pada Rumah Sakit Santo Vincentius yaitu sebanyak 212 orang tenaga profesi. Teknik sampling yang digunakan yaitu probability sampling. (Sugiyono, 2016: 151): "Probability Sampling adalah teknik pengambilan sampel yang memberikan peluang yang sama bagi setiap unsur (anggota) populasi untuk dipilih menjadi anggota sampel. Dengan menggunakan tabel penentu dalam buku (Sugyono, 2012: 161), jumlah sampel dari populasitertentu, bila jumlah populasi $=212$, kesalahan $10 \%$, maka jumlah sampelnya $=118$. Karena populasi berstrata, maka sampelnya juga berstrata. Stratanya ditentukan menurut masing- masing tenaga kesehatan harus proporsional sesuai dengan populasI.

Tabel 4. Sampel Penelitian

\begin{tabular}{|c|l|c|c|c|c|}
\hline No & Jenis Profesi & $\mathbf{N}$ & Alokasi Sampel & $\mathbf{S}=(\mathbf{N} / \mathbf{\Sigma N}) .118$ & $\begin{array}{c}\text { Sampel } \\
\text { (orang) }\end{array}$ \\
\hline 1 & Dokter & 18 & 118 & 10,02 & 10 \\
\hline 2 & Perawat & 140 & 118 & 77,92 & 78 \\
\hline 3 & Bidan & 23 & 118 & 12,80 & 13 \\
\hline 4 & Apoteker & 5 & 118 & 2,78 & 3 \\
\hline 5 & Asisten Apoteker & 3 & 118 & 1,67 & 2 \\
\hline 6 & Analis Kesehatan & 10 & 118 & 5,57 & 5 \\
\hline 7 & Radiografer & 3 & 118 & 1,67 & 2 \\
\hline 8 & Fisioterapis & 2 & 118 & 1,11 & 1 \\
\hline
\end{tabular}

*corresponding authors e-mail : Singkawangmelly.salty@gmail.com singgihatdmodjo3805@gmail.com Online ISSN: 2721-4230 | Print ISSN: 2721-4281 


\begin{tabular}{|c|l|c|c|c|c|}
\hline 9 & Penata Gizi & 2 & 118 & 1,11 & 1 \\
\hline 10 & Perekam Medik & 4 & 118 & 2,23 & 2 \\
\hline 11 & IPSRS-Kesling & 2 & 118 & 1,11 & 1 \\
\hline & Jumlah & $\mathbf{2 1 2}$ & & & $\mathbf{1 1 8}$ \\
\hline
\end{tabular}

Sumber: Data olahan 


\section{HASIL DAN PEMBAHASAN}

Analisis data yang digunakan dalam penelitian ini yaitu dengan cara tabulasi hasil kuisioner dimana sebelumnya item-item pertanyaan dalam kuisioner sudah dikategorikan dan diberikan pembobotan berdasarkan skala likert. Selanjutnya hasil tabuliasi dijumlahkan kemuadian diambil nilai rata-rata dan hasil nilai ratarata dikategorikan sesuai dengan indeks persepsi konsumen (Tki).

Tabel 5. REKAPITULASI HASIL PENELITIAN

\begin{tabular}{|c|c|c|c|}
\hline Variabel & Indikator & $\begin{array}{l}\text { Nilai } \\
\text { Rata- } \\
\text { Rata }\end{array}$ & $\begin{array}{c}\text { Penilaian } \\
\text { Interprestasi }\end{array}$ \\
\hline \multicolumn{4}{|c|}{ A. Faktor Higyene } \\
\hline \multirow[t]{3}{*}{ 1. Gaji } & $\begin{array}{l}\text { a. Jumlah gaji diterima sesuai } \\
\text { dengan upah minimum kota. }\end{array}$ & 2,95 & Cukup Setuju \\
\hline & $\begin{array}{l}\text { b. Gaji yang diterima sesuai } \\
\text { dengan beban kerja. }\end{array}$ & 2,53 & Cukup Setuju \\
\hline & $\begin{array}{l}\text { c. Gaji yang diterima mencukupi } \\
\text { biaya hidup. }\end{array}$ & 2,67 & Cukup Setuju \\
\hline \multirow[t]{2}{*}{ 2. Kondisi kerja } & $\begin{array}{l}\text { a. Kebersihan dan kenyamanan } \\
\text { dalam lingkungan kerja. }\end{array}$ & 3,87 & Setuju \\
\hline & b. Penerangan ruangan. & 3,92 & Setuju \\
\hline
\end{tabular}

\begin{tabular}{|c|c|c|c|}
\hline Variabel & Indikator & Nilai & Penilaian \\
\hline & & $\begin{array}{l}\text { Rata- } \\
\text { Rata }\end{array}$ & Interprestasi \\
\hline & c. Sirkulasi udara diruang kerja. & 3,53 & Setuju \\
\hline \multirow[t]{3}{*}{$\begin{array}{l}\text { 3. Hubungan } \\
\text { kerja }\end{array}$} & $\begin{array}{l}\text { a. Komunikasi dan kerjasama } \\
\text { antara sesama rekan kerja. }\end{array}$ & 3,99 & Setuju \\
\hline & $\begin{array}{l}\text { b. Komunikasi dan kerjasama } \\
\text { antara pimpinan dengan } \\
\text { karyawan. }\end{array}$ & 3,81 & Setuju \\
\hline & $\begin{array}{l}\text { c. Komunikasi dan kerjasama } \\
\text { team work dalam suatu } \\
\text { komunitas. }\end{array}$ & 3,90 & Setuju \\
\hline \multirow[t]{3}{*}{$\begin{array}{l}\text { 4. Keselamatan } \\
\text { Kerja } \\
\end{array}$} & $\begin{array}{l}\text { a. Adanya alur dan prosedur } \\
\text { dalam bekerja. }\end{array}$ & 3,97 & Setuju \\
\hline & $\begin{array}{l}\text { b. Perlengkapan keamanan dalam } \\
\text { bekerja. }\end{array}$ & 3,74 & Setuju \\
\hline & c. Keamanan dalam ruang kerja. & 3,75 & Setuju \\
\hline \multirow[t]{2}{*}{$\begin{array}{l}\text { 5. Kebijakan } \\
\text { perusahaan }\end{array}$} & $\begin{array}{l}\text { a. Peraturan yang berlaku } \\
\text { ditempat kerja. }\end{array}$ & 3,87 & Setuju \\
\hline & b. Sistem pengawasan kerja. & 3,55 & Setuju \\
\hline
\end{tabular}

*corresponding authors e-mail : Singkawangmelly.salty@gmail.com singgihatdmodjo3805@gmail.com Online ISSN: 2721-4230 | Print ISSN: 2721-4281 


\begin{tabular}{|c|c|c|c|c|}
\hline & \multicolumn{2}{|c|}{$\begin{array}{l}\text { c. Reward (hadiah) dan punishment } \\
\text { (hukuman) yang dikenakan } \\
\text { kepada karyawan. }\end{array}$} & 2,91 & Cukup Setuju \\
\hline & \multicolumn{2}{|c|}{$\begin{array}{l}\text { d. Komitmen pimpinan dalam } \\
\text { keputusan. }\end{array}$} & 3,47 & Setuju \\
\hline \multicolumn{3}{|c|}{ Total Rata-rata } & 3,55 & Setuju \\
\hline \multicolumn{5}{|c|}{ B Faktor Motivasional } \\
\hline \multirow{4}{*}{\multicolumn{2}{|c|}{ 1. Pekerjaan itu sendiri }} & $\begin{array}{l}\text { a. Pekerjaan yang } \\
\text { menyenangkan. }\end{array}$ & 3,97 & Setuju \\
\hline & & $\begin{array}{l}\text { b. Penempatan kerja sesuai } \\
\text { kompetensi. }\end{array}$ & 4,00 & Sangat Setuju \\
\hline & & $\begin{array}{l}\text { c. Pembebanan pekerjaan } \\
\text { terhadap karyawan. }\end{array}$ & 3,40 & Setuju \\
\hline & & d. Adanya rotasi kerja. & 3,42 & Setuju \\
\hline \multirow{3}{*}{\multicolumn{2}{|c|}{ 2. Tanggung jawab }} & $\begin{array}{l}\text { a. Kejelasan pembagian } \\
\text { tugas dan tanggung } \\
\text { jawab. }\end{array}$ & 3,79 & Setuju \\
\hline & & $\begin{array}{l}\text { b. Kesesuaian pekerjaan } \\
\text { dengan tanggung jawab. }\end{array}$ & 3,78 & Setuju \\
\hline & & $\begin{array}{l}\text { c. Pekerjaan dilakukan } \\
\text { sesuai standar } \\
\text { operasional. }\end{array}$ & 3,92 & Setuju \\
\hline \multirow{3}{*}{\multicolumn{2}{|c|}{ 3. Pengakuan }} & $\begin{array}{l}\text { a. Pengakuan terhadap } \\
\text { prestasi kerja oleh atasan } \\
\text { atau rekan kerja. }\end{array}$ & 3,54 & Setuju \\
\hline & & b. Adanya promosi jabatan. & 3,32 & Cukup Setuju \\
\hline & & $\begin{array}{l}\text { b. Keterlibatan karyawan } \\
\text { alam pengambilan } \\
\text { keputusan }\end{array}$ & 3,44 & Setuju \\
\hline \multicolumn{2}{|c|}{$\begin{array}{l}\text { 4. Peluang untuk maju } \\
\text { dan tumbuh }\end{array}$} & $\begin{array}{l}\text { a. Adanya pendidikan dan } \\
\text { pelatihan. }\end{array}$ & 3,82 & Setuju \\
\hline
\end{tabular}

\begin{tabular}{|c|l|c|c|}
\hline Variabel & \multicolumn{1}{|c|}{ Indikator } & Nilai & Penilaian \\
\hline & $\begin{array}{c}\text { Rata- } \\
\text { Rata }\end{array}$ & Interprestasi \\
\hline & $\begin{array}{l}\text { b. Kepuasan terhadap } \\
\text { kebebasan } \\
\text { pengembangan } \\
\text { kompetensi. }\end{array}$ & 3,67 & Setuju \\
\hline 5. Prestasi & c. Jenjang karier. & 3,60 & Setuju \\
\hline & $\begin{array}{l}\text { a. Penyelesaian pekerjaan } \\
\text { dengan tepat waktu. }\end{array}$ & 3,73 & Setuju \\
\hline
\end{tabular}

*corresponding authors e-mail : Singkawangmelly.salty@gmail.com singgihatdmodjo3805@gmail.com Online ISSN: 2721-4230 | Print ISSN: 2721-4281 


\begin{tabular}{|l|l|c|c|}
\hline & $\begin{array}{l}\text { b. Kecepatan dan ketepatan } \\
\text { dalam bekerja. }\end{array}$ & 3,86 & Setuju \\
\hline & c. Penilaian prestasi kerja. & 3,71 & Setuju \\
\hline Jumlah Nilai Rata-rata & $\mathbf{3 , 6 9}$ & Setuju \\
\hline
\end{tabular}

Sumber: Data Olahan

Berdasarkan data pada tabel 5 menunjukkan bahwa jumlah nilai rata-rata rekapitulasi hasil penelitian faktor motivasi hygiene 3,55 berada pada rentang interval 3,40 - 4,19 adalah setuju. Dapat dikatakan bahwa tenaga kesehatan pada Rumah Sakit Santo Vincentius Singkawang setuju terhadap faktor motivasi hygiene, dimana dari 17 faktor motivasi hygieneterdapat penilaian interprestasi responden paling dominan setuju yaitu sebanyak 12. Dan, jumlah nilai rata-rata faktor motivasional 3,69 berada pada rentang interval 3,40 - 4,19 adalah setuju. Selanjutnya dapat dipersepsikan bahwa tenaga kesehatan pada Rumah Sakit Santo Vincentius Singkawang setuju terhadap faktor motivasional, dimana dari 16 faktor motivasi motivasional terdapat penilaian interprestasi responden paling dominan setuju yaitu sebanyak 14. Jadi, tenaga kesehatan pada Rumah Sakit Santo Vincentius lebih dominan setuju dimotivasi dengan faktor motivasional dibandingkan faktor hygiene dengan alasan faktor motivasi hygiene merupakan hak-hak dasar pekerja yang harus diberikan oleh pemberi kerja sesuai dengan ketetapan perundang-undangan pemerintah dan standar pelayanan kesehatan menurut klasifikasi kelas rumah sakit. Dan, faktor motivasional merupakan upaya peningkatan mental dan perilaku yang baik dalam pencapaian kepuasan kerja. Selain itu, dorongan yang diberikan kepada penerima kerja agar para karyawan dapat menyelesaikan pekerjaan dengan efektif dan efisien, profesional dan produktif, dengan penuh semangat dan kinerja yang tinggi, mempertahankan loyalitas, dan kestabilan jumlah tenaga kerja, guna dapat mempercepat dalam pencapaian tujuan organisasi.

\section{SIMPULAN}

Berdasarkan hasil analisis dan pembahasan faktor-faktor motivasi kerja tenaga kesehatan pada Rumah Sakit Santo Vincentius Singkawang bahwa:

\section{Faktor Hygiene}

Sebagian tenaga kesehatan menyatakan cukup setuju dengan jumlah gaji yang dibayarkan sesuai dengan upah minimum kota dan dibayarkan setiap akhir bulan. Tenaga kesehatan juga menyatakan gaji yang diterima cukup sesuai dengan beban kerja yang dilaksanakan setiap hari dan dapat mencukupi biaya hidup sehari-hari. Selain itu, tenaga kesehatan cukup setuju dengan reward (hadiah) diberikan kepada karyawan yang telah bekerja selama 20 tahun berturut-turut tanpa berhenti kepadanya diberikan hadiah travelling secara berkelompok, dan selama 25 tahun berturut-turut tanpa berhenti kepadanya diberikan kenang-kenangan berupa (plakat) dan uang penghargaan, dan punishment (hukuman) yang dikenakan kepada karyawan berupa teguran lisan dan tertulis kepada karyawan

*corresponding authors e-mail : Singkawangmelly.salty@gmail.com singgihatdmodjo3805@gmail.com Online ISSN: 2721-4230 | Print ISSN: 2721-4281 
yang melakukan kesalahan atau pelanggaran agar karyawan disiplin, tertib dan bekerja sesuai peraturan karyawan dan tata tertib yang berlaku di Rumah Sakit Santo Vincentius Singkawang.

\section{Faktor Motivasional}

Tenaga kesehatan cukup setuju terhadap adanya promosi jabatan karena, pihak pimpinan memberikan promosi jabatan kepada karyawan yang berkinerja tinggi untuk menduduki kekosongan jabatan dalam stuktural berdasarkan syarat kualifikasi yang ditentukan untuk memenuhi kepentingan organisasi dan kebutuhan Rumah Sakit Santo Vincentius Singkawang.

\section{SARAN}

Berdasarkan pembahasan dan kesimpulan yang diambil, penulis memberikan beberapa saran yang kiranya dapat bermanfaat sebagai bahan pertimbangan bagi Rumah Sakit Santo Vincentius Singkawang bahwa:

\section{Faktor Hygiene}

Untuk faktor hygiene seperti variable gaji, Pihak pimpinan wajib memperhatikan dan memberikan hak-hak dasar buruh/pekerja berupa upah yang layak sesuai ketentuan upah minimum kota yang telah ditetapkan oleh Gubernur sesuai Undang-Undang nomor 13 tahun 2003 tentang ketenagakerjaan, untuk mendukung pembangunan nasional dalam mewujudkan kesejahteraan pekerja/buruh dan keluarganya dengan tetap memperhatikan perkembangan kemajuan dunia usaha. Untuk variable motivasi seperti kondisi kerja, hubungan kerja, keselamatan kerja, dan kebijakan perusahaan harus dipertahankan dan ditingkatkan agar karyawan dapat menyelesaikan pekerjaan dengan efektif dan efisien, dengan penuh semangat dan kinerja yang tinggi demi mempertahankan loyalitas, dan kestabilan jumlah tenaga kerja.

\section{Faktor motivasional}

Faktor motivasional seperti variable pekerjaan itu sendiri, tanggung jawab, pengakuan, peluang untuk maju dan tumbuh, dan prestasi harus dipertahankan dan ditingkatkan untuk peningkatan mental dan perilaku kerja karyawan yang baik dan berpotensi, profesional dan produktif, untuk dapat memberikan kontribusi bagi pencapaian tujuan organisasi Rumah Sakit Santo Vincentius Singkawang.

\section{DAFTAR PUSTAKA}

Afifudin. 2013, Dasar-Dasar Manajemen. CV ALFABETA, Bandung

Andi, Prastowo. 2011, Metode Penelitian Kualitatif Dalam Perspektif Rancangan Penelitian, Ar-Ruuz Media, Jogjakarta

Hasibuan, Malayu, S.P, 2012, Manajemen Sumber Daya Manusia, edisi revisi. Bumi Aksara, Jakarta

Mangkunegara, Anwar Prabu, 2011, Manajemen Sumber Daya Manusia Perusahaan, edisi kesepuluh, Remaja Rosdakarya, Bandung

Nawawi, H. Hadari, 2011, Manajemen Sumber Daya Manusia Untuk Bisnis Yang Kompetitif, Gajah Mada University Press, Yogyakarta 
Priansa, Donni Juni, 2016, Perencanaan \& Pengembangan SDM. Alfabeta, Bandung Sugiyono. 2012, Metode Penelitian Kuantitatif, Kualitatif, dan Kombinasi. Alfabeta, Bandung Sugiyono. 2016, Metode Penelitian Manajemen. Alfabeta, Bandung

Suparyadi, H. 2015, Manajemen Sumber Daya Manusia. Menciptakan Keunggulan Bersaing Berbasis SDM. CV Andi Offset, Yogyakarta

Sutrisno, H. Edy, 2010, Manajemen Sumber Daya Manusia, Kencana, Jakarta: Wibowo. 2011, Manajemen Kerja. edisi ketiga. Rarajawali Pers, Jakarta 